\title{
Evaluation of buyer's loyalty process in retail companies in Latvia under the conditions of globalization
}

\author{
Iveta Linina $^{1 *}$, Rosita Zvirgzdina ${ }^{2}$ \\ ${ }^{1}$ Turiba University, Graudu street 68, Riga, Latvia, LV 1058 \\ ${ }^{2}$ Turiba University, Graudu street 68, Riga, Latvia, LV 1058
}

\begin{abstract}
Retail sector has always played an important role in the Latvian economy. The success of a profitable retail business depends on meeting the needs of buyers and, in the long run, building relationships with the buyer. Process of attracting new buyers always involves spending more money, time and energy. In order for a company to retain existing buyers, it is necessary to develop a set of marketing activities that promote and ensure customer loyalty. The globalization of the market is also having a greater impact on retail companies, which makes them to look for solutions for competitiveness and development. In order to identify factors for competitiveness, the authors of the study have set out to investigate the customer loyalty-formation activities in Latvian retail companies. To reach a goal the authors of the paper will study theoretical basis of loyalty formation employing the monographic or descriptive method, the next step will be analysis of the retail development tendencies in Latvia and loyaltycreation activity level of the Latvian retail companies. This study will give retailers an understanding of the importance of loyalty and the need to build it for the competitiveness of retail businesses. The authors have summarized these theoretical aspects and have defined a common approach to loyalty building and provisions for it. After completing the research, the authors conclude that by understanding the essence and formation of loyalty, the company can manage this process and maybe loyalty can be one of the tools for ensuring competitiveness.
\end{abstract}

\section{Introduction}

Within context of market globalization, ensuring companies' competitiveness is a key factor. Focusing on consumers, researching their demand and satisfying their needs lead towards application of consumer relationship management within the company that has become an integral part of the business. According to the research, attracting a new buyer costs 5-10 times more than selling to an existing buyer, and the existing buyer spends $67 \%$ more money than new buyers [1]. Therefore, it is essential for the company to develop a system that will encourage the buyer to make a repeat purchase and result in loyalty. By

\footnotetext{
* Corresponding author iveta.linina@turiba.lv
} 
understanding and utilizing factors that make up consumer loyalty, the company gains greater customer confidence and significantly increases its competitiveness. By studying and understanding consumer behavior, a company can provide itself with significant competitive advantages. Businesses in Latvia do not have a sufficient understanding of consumer relationship management, and in particular the benefits thereof. The study looks at the factors behind consumer loyalty in retail businesses.

The study looks at the most common consumer loyalty models, although the process of building consumer loyalty is never complete, but it is rather a mechanism for business improvement. Different companies use different customer management systems, but the unifying aspect of all of them is a satisfied, loyal customer who would ensure company competitiveness in the long run.

The aim of this investigation is to find out the main factors behind the development of consumer loyalty in retail trade and to define the specifics of this process, that would allow retailers to improve their performance and ensure their competitiveness.

The following tasks were set to achieve the goal:

1. To analyze theoretical factors of consumer loyalty formation.

2. Identify the main factors and characteristics of consumer loyalty in the retail sector by the means of the consumer survey.

In order to determine the consumer loyalty trends in Latvia and to make proposals for companies to improve their consumer loyalty formation processes, the experts were interviewed and the following limitations were set: the problem is mainly investigated from a methodological point of view; Research period: June 1, 2019 to July 1, 2019.

The following research methods have been used: the logical-constructive method - in comparing theoretical material with empirical results; the graphical method for displaying and analyzing visually collected information and expert interviews. The methodological basis of this research consists of the the works and publications of various authors (R.Oliver, C.Homburg, I.Linina, etc.), which provide insight into the factors influencing and forming the consumer loyalty.

\section{Theoretical aspects of consumer loyalty}

Consumer satisfaction is one of the prerequisites for a long-term and profitable business relationship with consumers. This level of satisfaction can be expressed in different ways in the behavior of the consumer in the market, which also affects the success of the business. Consumers can only be engaged or loyal to businesses. It would be wrong to use these two terms as synonyms. One of the most important expressions of satisfaction is loyalty. Attracting new customers to businesses is significantly more expensive than retaining existing ones, as regular consumers spend more but pay less for the company [2]. Researchers [3] have found that maintaining only about $15-20 \%$ of the cost to attract new consumers is sufficient to sustain loyal consumers. Based on empirical research, other authors [4] argue that acquiring new consumers is 5-7 times more expensive than retaining existing consumers.

In order to draw conclusions about the nature of the concept of loyalty and the process of its formation, the authors of the study analyzed the views of other researchers on the problem. One-dimensional loyalty approach dominated early research. Loyalty was linked to the result of the consumer's behavior in the market, namely his preference for a certain offer on the market and decision-making on its purchase. In essence, this refers to the relationship of loyalty as a concept to repeated purchases [5]. There is a significant body of research whose authors argued about the importance of attitudinal loyalty to the consumer before the buying process [6]. Unlike the stochastic view of consumer behavior, these 
researchers emphasized the importance of the pre-purchase stage when marketing activities lead to a certain consumer experience, attitude and perception of the market situation.

Many authors believe that the concept of loyalty is based on a set of consumer preferences and beliefs that can be combined with the concept of "cognitive loyalty" [7]. The authors of the study essentially support researchers in their quest for a deeper understanding of consumer loyalty and attention to the details of their behavior before making a purchase, but believe it would be wrong to ignore behavioral loyalty as well, since without this endpoint, attitude research is meaningless.

Having identified the shortcomings of the one-dimensional loyalty model, the researchers suggest investigating this category from a two-dimensional point of view [8] and highlighting the four levels of loyalty that characterize the relationship between consumer attitudes to a particular offer and purchase loyalty, closed loyalty and positive loyalty. This approach provides an opportunity to analyze consumer loyalty not only from the point of view of the end result (repeated purchases), which can be due not only to loyalty but also to the psychology of consumer behavior. There were also weaknesses in the two-dimensional approach to the development of the nature of loyalty in research. The proposal to obligatory study and quantitative assessment of consumers' awareness of the offer was a particular objection. Publications appeared by authors of loyalty programs in companies that found such studies to be unhelpful and sometimes unfounded [9]. In other words, such studies are expensive and do not produce realistic results for the company.

In the late 20th and 21st centuries, research on the essence of loyalty and its practical application was influenced by the publications of researcher R. Oliver [10]. He does not object to the claim that the loyalty-building process is largely based on the level of consumer attitudes, but believes that loyalty is based not on two dimensions but on four dimensions. In this regard, the researcher, in the context of attitude loyalty, also highlights the emotional dimension (I buy because I like this offer) and the trust dimension (I buy because I trust this offer), which together with the cognitive dimension influence the decision to buy again. Other researchers tested a four-dimensional model using an example of Internet service (book and airline bookings) and found that it yields better results than other loyalty models [11]. For example, research has uncovered various causes and influencing factors for consumer loyalty to a product / brand.

Testing this model of loyalty dimensions, the authors themselves found that it did not always produce positive results, namely that trust loyalty is often unrelated to action loyalty, and this correlation was relatively low [12]. Also, model testing using the tourism industry example (survey of 727 respondents) did not support the concept of the model and rather endorsed the two-dimensional model of loyalty (exploration and action) [13].

Summarizing the theoretical aspects of the concept of loyalty, the authors of the study propose the following definition of loyalty. Loyalty is the result of the consumer perception of the offer (product, service, brand, etc.), leading to a positive attitude (cognitive, trustful and emotional) and a favorable attitude towards the company (repeated purchases, additional purchases, high consumption intensity, etc.).

Loyal consumers have the following characteristics of market behavior: They buy more and stay loyal for longer, are less sensitive to price increases, recommend other consumers buy and consume / use a particular product / brand that is beneficial to the company because:

- word-of-mouth communication costs nothing;

- Recommendations contain specific information based on consumption / use experience;

- Communication comes from friends and / or acquaintances you can trust.

In essence, consumer loyalty increases the value of a business because:

- Calls for lower consumer acquisition costs; 
- the development of a solid consumer database;

- Allows you to increase product / brand prices within certain limits.

- promotes product sales and profit growth;

- promotes a positive corporate image and reputation.

Of course, these characteristics of loyal consumers and the benefits to the company depend on the level of loyalty. Consequently, the loyalty building process needs to be studied in more detail [14].

Most empirical studies show that there is a strong correlation between consumer satisfaction and loyalty [15]. There is as yet no unanimous agreement on how this relationship manifests itself in a realistic way (progressive, degressive or otherwise). Some researchers believe that the type of relationship might depend on the market situation, the nature of the offer, and the specifics of the target audience. In markets with high competition, the relationship between consumer satisfaction and loyalty has been shown to be progressive graphical, whereas markets with relatively low competition intensity are characterized by a degressive graphical form [16]. Empirical research has shown that there is a correlation between consumer satisfaction and loyalty, which can be graphically represented by the S-shape, because only when the consumer is seduced, loyalty increases very quickly when he is in the indifference zone and loyalty in the frustration zone leads to with a decrease in loyalty [17]. Other researchers have found that there are sometimes seemingly illogical situations of satisfied but loyal consumers and dissatisfied and yet loyal consumers [18].

Summarizing the views of the above mentioned authors on the forms of relationship between consumer satisfaction and loyalty, the author of the paper compiled a matrix. Four levels of loyalty are captured: fake loyalty, no loyalty, true loyalty, and potential loyalty. Satisfaction-loyalty studies show that the relationship is controversial. Consumer loyalty is not automatically generated solely from consumer satisfaction, but requires management and marketing activities, social activities, and more. The company should develop (but, if so, develop) specific loyalty programs to attract consumers more closely.

Unlike research in the 20th century, in the 21 st century, researchers necessarily include satisfaction as part of their loyalty-building process, regardless of the research object. Although practically all researchers draw conclusions about specific features of the process, depending on the characteristics of the industry / product / brand. For example, when researching mobile service, researchers suggest using the following model of consumer satisfaction and loyalty [19] (see Figure 2). The authors of the model studied the satisfaction and loyalty of mobile service customers in China. A questionnaire was used for this purpose (541 respondents, $80 \%$ of them have higher education). The study concluded that:

1) trust, quality of service and perceived values have a significant impact on customer satisfaction;

2) Satisfaction and cost significantly influence customer loyalty;

3) Among perceived values, satisfaction is most affected by functional and emotional value, while social and monetary value have less impact.

From the author's point of view, this model can also be used in other industry / product / brand research, due to their specificity, but as mentioned above, trust and emotional value are related to loyalty dimensions rather than influencing factors. Customer costs are also a contentious issue. It may not be useful to highlight this indicator separately, as perceived monetary value already includes a comparison of the effect of consumption with costs.

Based on the analysis of the advantages and disadvantages of loyalty models, the author has developed and offers for practical use a conceptual model of consumer loyalty. This model is universal in nature, but it should be practically applied, taking into account industry / product / brand characteristics. 
As you can see, consumer loyalty building processes include the following logically related elements:

- factors (values) affecting loyalty;

- perception of consumer values;

- characteristics of the target audience;

- consumer satisfaction;

- dimensions of consumer loyalty.

Based on the analysis of specialist literature, pilot studies and the author's experience, the following features of the consumer loyalty model can be highlighted:

1) the consumer may be loyal to a point of sale (in-store, out-of-store,

2) the perception of the three factors above depends on the geographical, demographic, economic, social and psychological characteristics of the target audience;

3) Unlike other industries, retail can have a relatively large amount of fake loyal consumers;

4) attitude loyalty mainly refers to product / brand values and the product / brand value - consumer cost ratio, whereas behavioral loyalty to service quality;

5) the main consequence of consumer loyalty is repetitive purchases. Other signs of loyalty - low price sensitivity and positive word-of-mouth communication - are less specific as they do not relate to retail sales as a whole, but to individual products /brands.

Factors influencing

consumer loyalty

(antecedents)

\section{Consumer loyalty} dimensions

(dimensions)

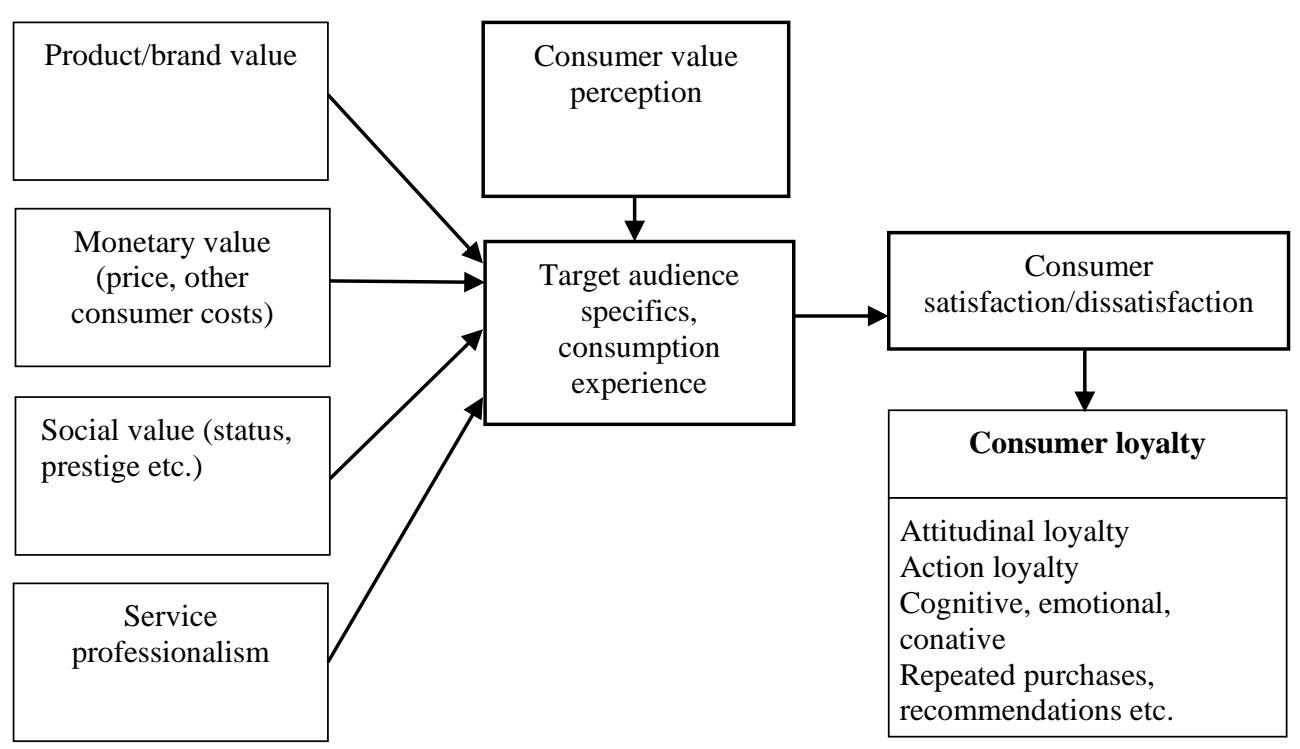

Fig.1. Conceptual model of consumer loyalty building [20]

From the authors' point of view, the proposed model can be applied to building consumer loyalty in the retail businesses. 
The subject of this study is retail. Retail is an intermediary in the distribution channel for products. A product distribution channel is a set of interconnected companies that participate and perform all functions in the process of transferring, distributing, promoting and selling products and related values from the producer to the consumer [21]. The development of retail companies in recent years shows that retail trade as a whole is a profitable business in Latvia, which is also evidenced by the dynamic growth of turnover every year since the end of the global economic crisis.

Expert methods are increasingly used in the evaluation and forecasting of socioeconomic processes. The expert survey is mainly used for diagnosing and forecasting industry problems and analyzing and solving research problems. An expert is a qualified specialist in the field who expresses his or her opinion, for example, in the evaluation of a particular activity. In addition, the expert can evaluate various (significant and insignificant) factors, goals, better ways of achieving them, performance, etc. Therefore, the authors of the thesis chose the survey method of experts, which is considered as one of the most suitable methods for assessing loyalty in the retail sector. Unlike statistical methods, experts, due to their experience and knowledge of the situation in the retail trade industry, take into account several factors that cannot be analyzed. The authors followed four steps in the implementation of the expert survey method.

\section{Results of the study}

1. Preparation of expert survey. During this phase the following tasks were solved: the problem to be investigated was formulated and the purpose of expertise was specified to evaluate the processes of loyalty forming in the telecommunications sector in Latvia; based on the purpose of the expertise as well as the specificity of its object, a specific expert method was selected - a survey with structured questions; a questionnaire was developed.

2. Selection of experts and composition of the expert group. At this stage, the numerical composition of the expert group was determined, the competence of the expert group was analyzed and the necessary information was provided to the experts. After consultation with a number of experts and given the expertise of the experts in the field, the authors identified a group of nine experts. In selecting the experts, the authors of the paper were guided by the experience and knowledge of the specialists and their ability to understand the process as a whole. Potential experts responded to questions about loyalty factors and peculiarities of retail and rated their level of competence on each of these points, with a maximum score for the area in which the specialist is most focused. The individual evaluations of each specialist were then compared by the study authors to the average self-assessment of potential experts on all questions. Numerically, the level of competence of a potential expert was assessed by the formula. As a result of the selection of experts, a group of experts was set up to include selected experts.

3. Characteristics of the expert survey. The expert survey was conducted in June-July 2019. Based on the objectives of the expertise and taking into account the peculiarities of the expert group, the authors selected the following characteristics of the expert survey: an individual survey, in which experts participate independently; off-site survey where experts provide individual answers without the direct assistance of expert organizers; closed questionnaire, where each expert is not informed of the answers of the other experts; closed-ended questions where each question (on a Likert scale in a 10 -point scale where 1 is very low but 10 very high) is preceded by a certain scale and the expert only has to select one of the quantitative grades. 
4. Statistical methods of processing and analysis of peer reviews. If peer reviews are given, extensive statistical analysis is possible. Using the SPSS software, the authors calculated the following parameters: sum of expert evaluation, mean arithmetic expert evaluation $\left(\mathrm{X}^{\overline{)}}\right.$, median $(\mathrm{Me})$; mod $(\mathrm{Mo})$, amplitude of variation, standard deviation, coefficient of variation.

In retail, the consumer loyalty is a guarantee of the company's sustainable development and competitiveness. Based on the conceptual model of building consumer loyalty, four blocks of questions were created - assortment of goods, including availability of local and organic products, price level, company prestige and status, and quality of service. Next, the authors of the study carried out the processing and analysis of peer reviews.

Table 1. Expert evaluation of loyalty factors in retail trade in Latvia (Autors)

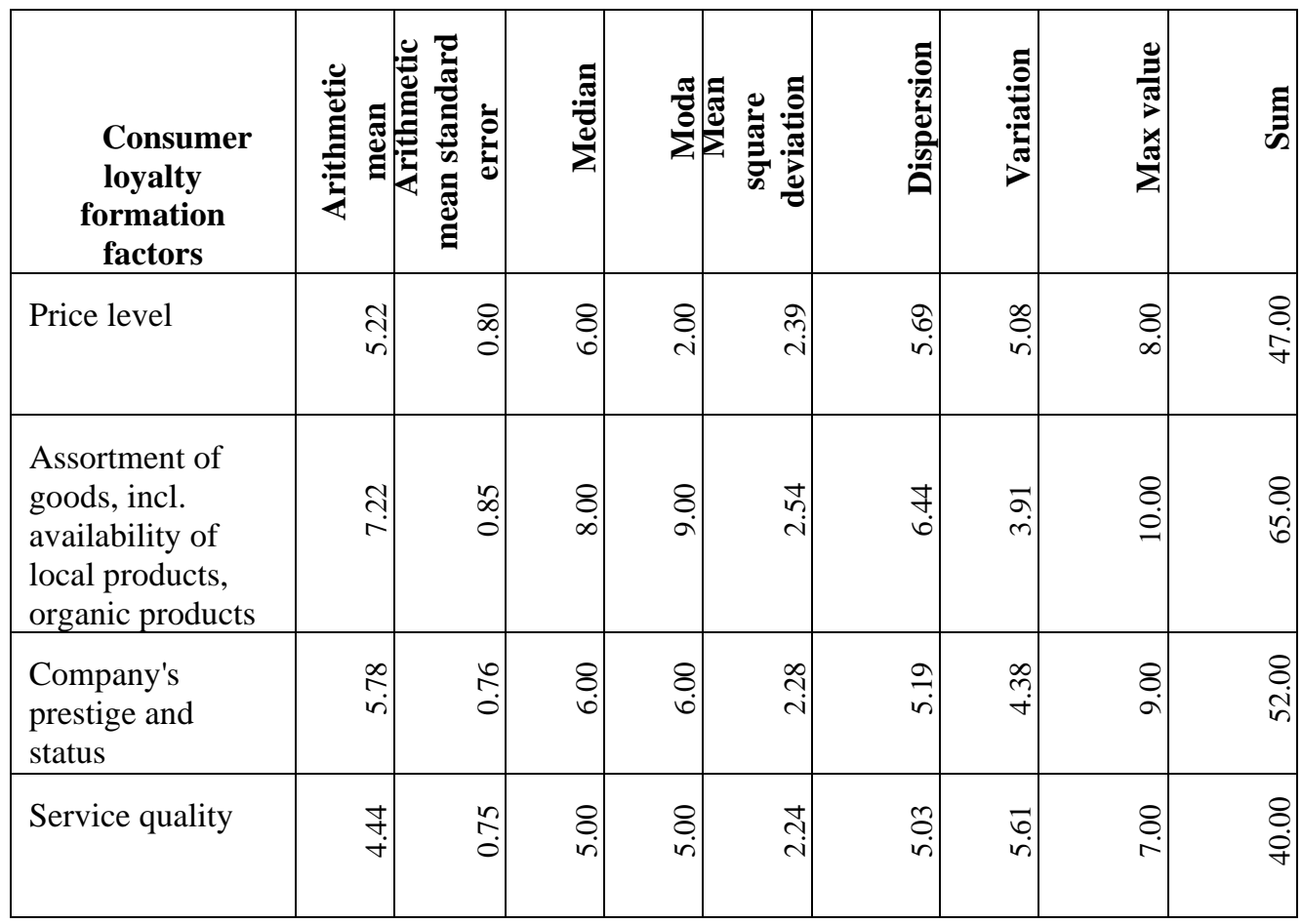

In order to evaluate the factors affecting loyalty formation in Latvian retail companies, the authors of the study carried out in-depth processing and analysis of the results of the expert survey (see Table 1). As can be seen, the experts gave the lowest rating to the quality of service $\left(\mathrm{X}^{-}=4.44 ; \mathrm{Me}=5.0 ; \mathrm{Mo}=5.00\right)$. It can often be concluded that this factor is not linked to consumer loyalty, which can play a crucial role in the competition in the event of an increase in shopping. The second lowest evaluation is the price level in the company. This is an important indicator of the competitiveness, but it must always be linked to the price-quality ratio, which has also been pointed out by experts $\left(\mathrm{X}^{-}=5.22 ; \mathrm{Me}=6.0\right.$; $\mathrm{Mo}=$ 2.00). Above average rating was assigned to the company's prestige and status $\left(\mathrm{X}^{-}=5.78\right.$; $\mathrm{Me}=6.00 ; \mathrm{Mo}=6.00$ ), but, of course, here too companies have to contribute to their corporate image. The factor most valued was the assortment of goods offered by retail companies, including the supply of local and ecological products $\left(\mathrm{X}^{-}=7.22 ; \mathrm{Me}=8.00\right.$; Mo $=9.00)$. It can be concluded that Latvian retailers pay much attention to this factor.

In addition, the signs of forced loyalty, such as the location of a retail business, appeared. In general, it should be noted that ratings have relatively low value and a high 
degree of variation (see Table 1). Besides that, there is a strong tendency - the lower the arithmetic mean $\left(\mathrm{X}^{\overline{)}}\right.$, the greater is the amount of variation. This means that the valuations of experts differ from company to company.

\section{Conclusions}

1. Based on research and literature analysis, the following features of the consumer loyalty model can be highlighted: The consumer may be loyal to a point of sale (instore, out-of-store, e-commerce, etc.), mainly due to the following factors: the existence of a product / brand that he is comfortable with; satisfaction with the "product / brand value - consumer cost" ratio; satisfaction with the quality of service; relatively less loyalty levels are influenced by social factors (excluding visitors to elite shops).

2. As a result of the expert survey, which was based on the proposed loyalty factor model (see Fig. 1), it can be concluded that the Latvian retail companies do not associate the service quality and price policy with the customer loyalty factors. Experts have also pointed out that globalization can be a major problem for non-competitiveness. It is also very important for retail companies to develop a corporate image strategy so that the process is focused on ensuring customer loyalty. The assortment of retailers must also be based on customer demand and expectations in order to increase satisfaction with existing supply.

3. The study also found that the location of the trading venue is an important factor in choosing a venue. All experts pointed out that as the number of sales outlets increased, this forced loyalty would diminish.

4. This study did not address retail business marketing activities such as loyalty programs, which experts also identified as an important factor in building loyalty.

\section{References}

1. J.L. Anderson, L.D. Jolly, A.E. Fairhurst, Customer relationship management in retailing: a content analysis of retail trade journals. Jaournal of Retailing and Consumers services, November, 14(6), (2007)

2. H. Karjaluoto, C. Jayawardhenda, M. Leppaniemi, M. Pihestrom, How value and trust influence loyalty in wireless telecommunications industry. Telecommunications Policy, 636-649 (2012).

3. W. Mueller, H.J. Riesenbeck, Wie aus zerbriedenen Kunden auch anhaengliche Kunden Werden. Harvard Manager, 3(13), s. 69 (1991)

4. A. Hermann, F. Huber, Kundenloyalitat desErfolgsdeterminante im Marketing. Journal fur Betriebswirts - chaft, 47, 1, 4-25 (1997)

5. F.M. Bass, The Theory of Stochastic Preference and Brand Switching. Journal of Marketing Research, 11, 1-20 (1997)

6. S.J. Backman, J.L. Crompton, The usefulness of selected variables for predicting activity loyality. Leisure Sciences, 13, 205-220 (1991)

7. J. Jacoby, R. Chestnut, Brand loyality measurement and management. New York, Willey (1978)

8. A.S. Dick, K. Basur, Customer loyality: Toward an integrated framework. Journal of the Academy of marketing Science, 22(2), 99-113 (1994) 
9. T. Jones, S.F. Tayeor, The conceptual domain of service loyality: How many dinunsions? Journal of Services Marketing, 21 (1), 36-51 (2007)

10. R.L. Oliver, Satisfaction: A Behavioral Perspective on the Consumer. (New York, 1997)

11. L.C. Harris, M.H. Goode, The four level of loyality and the pivotal roll of trust: A study of online service dynamics. Journal of Retailing, 80, 139-158 (2004)

12. K. Back, The effects of image conquence on customer satisfaction and brand loyality in the lodging industry. Unpublished Doctoral dissertation, The Pennsylvania State University (2001)

13. M.P. Ritchard, M.E. Mavitz, O. Howard, Analysing the communitment loyality link in service contexts. Journal of the Academy of Marketing Science, 27(3), 333-348 (1999)

14. I. Linina, R. Zvirgzdina, The Consumer Loyality formatiom Process and Its Particularities in the Retail Sector. Vilnius (2016)

15. V. Mittal, W.A. Kamakura, Satisfaction, Repurchase, intend and Depurchase Behavior: Investigating the Moderating Effect on Customer Characteristics. Journal of Marketing Research, 38(1), 131-142 (2001)

16. A. Homburg, A. Giering, Kundenzufriedenheit: Ein Garant fur Kundenloyalitat? Absatzwirtschaft, 1-2, 82-91 (2000)

17. K. Matzler, H. Pechlaner, Management von Kundenzufriedenheit: 10 Trugschlusse. Vom Alten zum neuen Tourismus, Beitrage aus Forschung und Prahis, (Innsbruck, Studia Verlag, 2011)

18. M. Cano, S. Drummond, C. Miller, S. Barclay, Learning From others: Benchmarking in diverse tourism enterprises. Total quality Management, 12 (7,8), 976 (2001)

19. Z. Deng, Lu. Yaobin,, W. Kwo Kee, Z. Iinlong, Understanding customer satisfaction and loyality: Anempirical study of mobile instant messages in China. International Journal of Information Management, 30, 289-300 (2010)

20. P. Kotler, G. Armstrong, V. Wong, J. Saunders, Principles of Marketing. 5th Europe an Edition, (Pentice Hall, 2011)

21. I. Linina, R. Zvirgzdina, The Consumer Loyality formatiom Process and Its Particularities in the Retail Sector. Vilnius (2016) 